\title{
Guillain-Barre Syndrome: Case Report
}

\author{
Nasira Mustafa*, Hajra Sarwer, Afzal M, Arif M \\ Department of Nursing, University of Lahore, Pakistan
}

\begin{abstract}
Guillain Barre Syndrome (GBS) is acute onset. It is auto immune mediated neuropathy. Nutrition play important role in GBS patients. GBS is no traumatic disorder. It is paralytic diseases in developing countries. The auto antibodies are present against the various antigens in peripheral regions. The occurrence of this disease is very rare. The incidence of the GBS is 0.4 to 1.7 per million people per year. GBS have subtypes acute motor axonal neuropathy (AMAN), and ADIP acute inflammatory demyelinating polyneuropathy.

A 12 years old male patient admitted in Government hospital with the complaint of inability to walk and stand. His lower extremities become weak. He cannot stand $u p$ and he was unable to walk. After hospitalization treatment given to patient after few days he was discharged. He referred to nutritional support. A team gives him medical therapy.

After labs and blood tests, the result is obtained GBS positive. A significant result obtained than it would be treated.

GBS is very rare disease. The diagnosis is very difficult. In this condition the patient progressively weak their extremities. The disorder in limbs weakness increase day by day.
\end{abstract}

Keywords: Diet; Guillain-barre-syndrome; Nutrition support

\section{INTRODUCTION}

Many patients have neuro musculo-skeletal problems. Some of them come with complaints of extremities. The neuropathy of peripheral is seen in clinical practice. Due to alcohol; diabetes and poor diet also cause neuropathy. In extremities numbness and sclerosis occur. The main cause of muscles weakness in body is Guillain-Barre-Syndrome [1,2].

This disease occurs due to Campylobacter jejuni and other viruses including Cytomegalovirus and Epstein Barr Virus. The disorder includes several sub types. From the study of USA, Europe and Australia the incidence of GBS is round about 1-3/100000 population. The diagnosis of this diseases based on clinical examination and history. The electro diagnostic testing and cerebro spinal fluid analysis provide supportive diagnosis. The plasma exchange and immunoglobulin intravenous is effective treatment in GBS [3].

Acute GBS starts from the fingers or finger tips of the foot. After sometimes it becomes worst. Weakness of legs and arms, difficulty in walking and stairs climbing.

Guillain-Barre-Syndrome is the main causes of the paralysis in neuromuscles. GBS mainly have subtypes. Acute motor axonal neuropathy (AMAN). Another subtypes is acute inflammatory demyelinating polyneuropathy (AIDP).
The most common and symptoms are the weakness of the limbs is areflexia and the paralysis. Other than Acute motor axonal neuropathy and acute inflammatory demyelinating polyneuropathy, the Miller Fisher Syndrome. The one of the most common disorder is Miller Fisher Syndrome. It is the immune mediated disease. In these disease ataxia areflexia symptoms involved. This disorder is treated by the immunoglobulin and plasma exchange.

GBS is heterogeneous autoimmune disease. Autoantibodies are present against various antigens in peripheral nerves and nerves. The incidence of GBS is $0.4-1.7$ case per million person per year. The occurrence of this disease is rare. This disease is diagnosed by clinically. The Miller Fisher Syndrome was based on acute clinical course.

\section{CASE PRESENTATION}

A 12 years old boy with GBS in Government hospital. Chief complaints of the patientwere unable to stand and walk, involvement of the lower extremities upwards. Five days before patient hit his back with bedside. IVIg is given during hospitalization. Laboratory tests are given Table 1 .

At the $1^{\text {st }}$ day of the hospitalization patient kept NPO. Inj Methyl is given stat than for three days. Inj IVIg $30 \mathrm{gm}$ is given iv stat than for three days. Inj D/W $550 \mathrm{ml}$ with $\mathrm{Kcl} 2 \mathrm{cc}$ is given to patient. Inj Diclo, Cap Gabapentine for OD. At the same time the parental

Correspondence to: Nasira Mustafa, Department of Nursing, University of Lahore, Pakistan, Tel: +923351775924; E-mail: nasiramustafa924@gmail.com

Received: May 13, 2019; Accepted: May 28, 2019; Published: June 04, 2019

Citation: Mustafa N, Sarwer H, Afzal M, Arif M (2019) Guillain-Barre Syndrome: Case Report. Health Care Current Reviews 7: 246. doi: 10.35248/2375-4273.19.7.246.

Copyright: (C) 2019 Mustafa N, et al. This is an open-access article distributed under the terms of the Creative Commons Attribution License, which permits unrestricted use, distribution, and reproduction in any medium, provided the original author and source are credited. 
Table 1: Laboratory tests.

\begin{tabular}{|c|c|}
\hline Total bilirubin & $0.8 \mathrm{mg} / \mathrm{dl}$ \\
\hline $\mathrm{PCO}_{2}$ & $27.8 \mathrm{mmHg}$ \\
\hline $\mathrm{PO}_{2}$ & $68.3 \mathrm{mmHg}$ \\
\hline $\mathrm{Hcl}$ & $29 \%$ \\
\hline $\mathrm{HCO}_{3}$ & $15.4 \mathrm{mmol} / \mathrm{L}$ \\
\hline $\mathrm{TCO}_{2}$ & $16.3 \mathrm{mmol} / \mathrm{L}$ \\
\hline $\mathrm{Beb}$ & $-8.3 \mathrm{mmol} / \mathrm{L}$ \\
\hline $\mathrm{Beecf}$ & $-10.4 \mathrm{mmol} / \mathrm{L}$ \\
\hline $\mathrm{SBC}$ & $17.6 \mathrm{mmol} / \mathrm{L}$ \\
\hline $\mathrm{A}$ & $112.7 \mathrm{mmol} / \mathrm{L}$ \\
\hline $\mathrm{A}-\mathrm{ADO}$ & $44.4 \mathrm{mmHg}$ \\
\hline $\mathrm{a} / \mathrm{A}$ & 0.6 \\
\hline $\mathrm{RL}$ & 0.7 \\
\hline $\mathrm{PO}_{2} / \mathrm{FIO}_{2}$ & $326.7 \mathrm{mmHg}$ \\
\hline $\mathrm{SO}_{2} \%$ & 92.8 \\
\hline $\mathrm{Hb}$ & $9.7 \mathrm{~g} / \mathrm{dL}$ \\
\hline
\end{tabular}

nutrition also started. In this disorder the electrolyte balance is also necessary. Soft diet and fluids also necessary. The care and nutrition support is important as like patient in CCU. The lacking or starvation of diet also leads to GBS. According to the need of patient the minerals and water also given [3].

In physical examination no neurological and orthopaedic findings. All the labs send. According to the result of labs GBS diagnosed. Some features rule out, no evidence of diphtheria, no porphyria, no poliomyelitis. In this situation pt. take not only medication, he also take palliative care. Patient is fully cooperated [2].

During examination he had no fever, respiratory infection and no gastroenteritis. The signs and symptoms of the GBS is sensations of pins, needles on fingers toes wrist or ankles. Unable to walk unable to speak. In this disorder severe condition leads to death [4].

GBS treatment depends on the condition of patient either they are acute, severe, chronic. Corticosteroids are not beneficial. Plasma exchange is effective therapy in this disorder. In every cases of this disorder the pain management and psychological support should be given [2].

Plasma exchange and immunoglobulin therapies are very effective In GBS patient's multidisciplinary care is good need to manage the complication. With this psychosocial support is also necessary. Physiotherapy and rehabilitation for patient is effective [5].

Patients have less or absence of deep tendon reflexes, in affected peripheral areas. The lumber puncture always done in those patients which have GBS. In the suspected patients the lumber puncture is done and white CSF is examined. If the protein level is increased the GBS is suspected.

\section{DISCUSSION}

Guillain-Barre-Syndrome is a disorder, which is acute areflexic polyneuropathy in autoimmune system. In this disorder weakness reach on the peak minimum 4 weeks. GBS have various sub types. The sub types treated with different treatment some patients with acute effect of GBS others are severe. Some want ventilator support. In this disorder immunoglobulin iv is given. In some patients plasma exchange is effective $[6,7]$.
In this disorder the diagnosis is very difficult because lack of test reports. The ethology of GBS is unclear. It is immune mediated disease. Peripheral nervous involves after this it involves the axonal. Mostly patients develops weakness in lower extremities, the reason is demyelination of the nerves. Paralysis of lower extremities [8]. This may acute, chronic. It depends on the destruction of nervous system. In this condition muscles stretch and sensation may be loss. Patient is unable to walk, stand and climb stairs. The pathogenesis of the GBS is edematous changes in the roots of the nerves at the junction of the anterior and posterior roots. At this time myelin sheeth become irregular at the $3^{\text {rd }}$ day of onset. After this phagocytes appear. This appears in rare cases which may leads to death.

In physiologic and variables it is stated that daily activities and physical burden leads to fatigue than GBS occur. In this way limbs become weak $[9,2]$.

\section{CONCLUSION}

Guillain-Barre-Syndrome is neurological disorder. In this disease the peripheral region disturbed. In this disorder the lower extremities become weak. Patient unable to walk, stand or run. After the proper tests, labs, than it would be diagnose. This may be acute severe or life threatening. It can be treated with immunoglobulin IV, plasma exchange or palliative care. In GBS the major subtype is AMAN in the eastern countries and South American countries. By epidemiologically this subtype is growing very rapidly. GBS related with the high risk of mortality rate due to progressive in weakness gradually.

\section{REFERENCES}

1. Meythaler JM. Rehabilitation of Guillain-Barré syndrome. Arc Phys Med Rehabil. 1997;78(8):872-879.

2. Pikula JR. Guillain-Barre Syndrome: A case report. J Canadian Chiropractic Assoc. 1995;39(2):80.

3. Mazidi M, Imani B, Norouzy A, Rezaei P. Guillain Barre Syndrome: A case report. Int J Hosp Res. 2013;2(2):91-93.

4. Modupalli C, Sriramulu C, Gopineni YPR, Diviti R. Acute Guillain Barre Syndrome. A Case report in Pediatrics. J Acute Dis. 2017;6(2):89.

5. Kuwabara S, Yuki N. Axonal Guillain Barre Syndrome: Concepts and controversies. Lancet Neurol. 2013;12(12):11801188 .

6. Van DPA, Ruts L, Jacobs BC. Clinical features, pathogenesis, and treatment of Guillain Barre Syndrome. Lancet Neurol. 2008;7(10):939-950.

7. Yuan J, Zhang J, Zhang B, Hu W. The clinical features of patients concurrent with Guillain-Barre syndrome and myasthenia gravis. Neurosciences (Riyadh). 2018;23(1):66-70.

8. Misawa S, Kuwabara S, Sato Y, Yamaguchi N, Nagashima K, Katayama K, et al. Safety and efficacy of eculizumab in GuillainBarré syndrome: a multicentre, double-blind, randomized phase 2 trial. Lancet Neurol. 2018;17(6):519-529.

9. Garssen MPJ, Bussmann JBJ, Schmitz PIM, Zandbergen A, Welter TG, Merkies ISJ, et al. Physical training and fatigue, fitness, and quality of life in Guillain Barre Syndrome and CIDP. Neurol. 2004;63(12):2393-2395. 